\title{
Lexical Access in Phrase and Sentence Production: Results from Picture-Word Interference Experiments
}

\author{
AnTJe S. MeYeR \\ Max Planck Institute for Psycholinguistics, Nijmegen, The Netherlands
}

\begin{abstract}
Four experiments investigated the span of advance planning for phrases and short sentences. Dutch subjects were presented with pairs of objects, which they named using noun-phrase conjunctions (e.g., the translation equivalent of "the arrow and the bag") or sentences ("the arrow is next to the bag',). Each display was accompanied by an auditory distractor, which was related in form or meaning to the first or second noun of the utterance or unrelated to both. For sentences and phrases, the mean speech onset time was longer when the distractor was semantically related to the first or second noun and shorter when it was phonologically related to the first noun than when it was unrelated. No phonological facilitation was found for the second noun. This suggests that before utterance onset both target lemmas and the first target form were selected. (c) 1996 Academic Press, Inc.
\end{abstract}

It is generally agreed upon that speakers prepare utterances in parallel at different planning levels while speaking at the same time. This assumption is almost unavoidable given the large number of planning levels implicated in theories of language production and the fact that speech is usually quite fluent. Yet, how speakers coordinate planning and talking with each other is largely unknown. The present research addresses this question. I first outline the working model of language production recently proposed by Bock and Levelt (1994) and review the available evidence about the temporal coordination of speech planning and articulation. Then four experiments that investigate how far ahead speakers plan noun phrase conjunctions, such as "the dog and the table,' and short sentences, such as "The dog is next to the table,' ' before initiating the utterance are presented.

Bock and Levelt (1994) partition utterance

The author thanks Herbert Baumann and John Nagengast for technical support, Jaap Parqui for selecting and testing the materials, Yvonne Rijs for running the experiments, and Pim Levelt, Ardi Roelofs, and the reviewers for helpful comments on the manuscript. Address correspondence and reprint requests to A.S. Meyer, Max Planck Institute for Psycholinguistics, Postbus 310, NL6500 AH Nijmegen, The Netherlands. E-mail: asmeyer@ mpi.nl. planning into three main levels of processing: the message, the grammatical, and the phonological levels (see Dell, 1986 and Garrett, 1980, 1982, 1988, for closely related views). The message is a prelinguistic specification of the intended meaning of the utterance. It is the input for the grammatical level of processing. Grammatical encoding comprises two components, namely, first, functional encoding, which includes lexical selection and function assignment, and, second, positional encoding. Lexical selection is the choice of lexical concepts and the associated lemmas. Lexical concepts can be equated with word meanings (but see Bierwisch \& Schreuder, 1992) and lemmas with specifications of the syntactic properties of words. The defining feature of lexical concepts (as opposed to other concepts) is that they are directly linked to lemmas. Function assignment is the assignment of lemmas to grammatical roles, such as subject or direct object. Positional encoding is the determination of the serial order of the lexical elements in the utterance. The result of grammatical encoding is the syntactic structure of the utterance.

The sound form of the utterance is constructed during the next major processing step, called phonological encoding. This process involves the retrieval of the phonological segments and metrical properties (e.g., the stress 
pattern and number of syllables) of the lexical items from the mental lexicon, the creation of prosodic units such as phonological words and phrases, the generation of intonation, and the selection of articulatory gestures (for details see Levelt, 1989, 1992; Levelt \& Wheeldon, 1994).

There is a substantial body of evidence supporting the distinction between the grammatical and the phonological levels of processing (for an extensive discussion see Levelt, 1989). First, there is speech error evidence. Word exchanges (e.g., "give the baby to the banana" instead of "give the banana to the baby") differ from sound exchanges (e.g., "'get my care hut" instead of "get my hair cut'") in the error units (whole words vs segments) and in the constraints they obey. The words involved in word exchanges typically belong to the same grammatical class and are often members of different phrases within a clause. By contrast, the words involved in sound exchanges often do not belong to the same grammatical class and are usually close neighbors in the syntactic surface structure. This suggests that word exchanges arise while the processor treats words as units and is sensitive to their syntactic class but not to their order in the surface structure, whereas sound exchanges arise after the word order has been established while the word forms are being built. Thus, word exchanges are likely to originate during the first part of grammatical encoding, i.e., during functional encoding, and sound errors during phonological encoding.

Second, tip-of-the-tongue states, in which speakers claim to know a word without being able to retrieve its phonological form, suggest that the form of a word may be dissociated from its meaning (see, for instance, Brown, 1991; Burke, MacKay, Worthley, \& Wade, 1991). This implies that word forms are stored and accessed separately from word meanings. Studies of lexical access in aphasic patients support this conclusion (Butterworth, 1992; Garrett, 1992; Goodglass, Kaplan, Weintraub, \& Ackerman, 1976; Le Dorze \& Nespoulous, 1989). Finally, there is experimental evidence showing that in picture naming the retrieval of the lemma of a word begins before the retrieval of its form (Schriefers, Meyer, \& Levelt, 1990; see Levelt, Schriefers, Vorberg, Meyer, Pechmann, \& Havinga, 1991, for related work and Dell \& O'Seaghdha, 1991, 1992, for a critical discussion).

The present research investigates the size of the grammatical and phonological planning units. Some evidence concerning this issue comes from analyses of speech errors and hesitations. As mentioned above, the error span is wider for word than for sound exchanges, suggesting that the planning units are larger at the grammatical than at the phonological level. As word exchanges typically involve words from different phrases within the same clause, the clause might be an important planning unit at the grammatical level. This hypothesis is supported by the observation that pauses are more likely to appear between than within clauses (e.g., Ford, 1982; Ford \& Holmes, 1978; Holmes, 1988). Sound exchanges almost always involve words from the same phrase-often, in fact, adjacent words. Thus, the phonological planning units probably comprise not more than one or two words within a phrase.

A number of studies have sought to determine the units of sentence production experimentally. Lindsley $(1975,1976)$ asked subjects to describe pictures of actions and varied, among other things, the length of the required utterances. Speakers took less time to initiate subject-only utterances (e.g., "the man') than subject-verb ("the man greets") and subject-verb-object utterances ("the man greets the girl'"), which did not differ in onset latencies. One account of these findings is that some verb-related, but no object-related, planning took place before utterance onset.

Kempen and Huijbers (1983) investigated whether there is any lexical, or only conceptual, processing for noninitial parts of an utterance before speech onset. Their subjects, who were native speakers of Dutch, first repeatedly described a set of pictures using subject-verb or verb-subject utterances, which occur, for instance, in questions (e.g., "komt Peter?" (does Peter come?)) and in main clauses starting with adverbials (e.g., "hier komt Peter", (here comes Peter)). In the second part of the 
experiment, the subjects were instructed to use new names for the actions. For instance, instead of "slaan', (Dutch for 'to beat') they should say "'meppen"' (to slap). This manipulation should affect the selection of the verb, but not the visual processing of the display. The change of verb led to an increase in mean utterance onset latency. This effect was stronger for verb-subject than for subjectverb utterances, indicating that for subjectverb utterances only some, but not all, of the lexical processing for the verb was done before utterance onset. Kempen and Huijbers proposed that the verb lemma, but not its form, was selected before utterance onset.

Compatible results were obtained by Levelt and Maassen (1981). They asked subjects to describe moving figures with easy or difficult names. The difficulty of the names had been established in a pretest and was defined as the reaction time difference between naming and recognition latencies for the figures. When both figures moved in the same direction, subjects used noun-phrase conjunctions (e.g., the Dutch translation equivalent of "the triangle and the circle go up") more often than sentence conjunctions ("the triangle goes up and the circle goes up'). Interestingly, utterance onset latencies were longer for the preferred NP-conjunctions than for sentence conjunctions. According to Levelt and Maassen, this reaction time difference arose because for an NP-conjunction the lemmas of both nouns were retrieved before utterance onset, whereas for a sentence conjunction beginning with a simple NP only the lemma of the first noun was retrieved. Thus, the unit of advance planning at the grammatical level might be the subject NP. Regardless of the syntactic structure, onset latencies were affected only by the difficulty of the name of the first, but not of the second, figure. Levelt and Maassen located the effect of naming difficulty at the level of word forms and concluded that only the form of the first, but not of the second, word was retrieved before speech onset.

Schriefers (1992, 1993) investigated grammatical encoding using the picture-word interference paradigm. In one experiment (Schriefers, 1992), Dutch subjects were pre- sented with pictures of colored objects which they described using adjective noun phrases (e.g., "groen huis"' (green house)). Superimposed on each picture appeared a written word, the so-called distractor. The mean reaction time was longer when the distractor was a member of the same semantic category as the target noun than when it was an unrelated noun and much faster when it was the target noun itself. No reaction time difference was obtained between color and unrelated adjectives, but the mean reaction time was shorter when the distractor was the target adjective itself. Schriefers concluded that on most trials the subjects retrieved the adjective and the noun lemma before utterance onset and that the slowest process, which was noun retrieval, determined the speech onset. However, on some trials, especially when the distractor was the target adjective, the subjects started to speak as soon as they had retrieved the adjective stem. Thus, subjects might have a certain degree of flexibility in the choice of the planning units.

Ferreira (1991) investigated the planning units in sentence production using a sentence reiteration task. On each trial, subjects first read a sentence, then the sentence was removed, and upon presentation of a response cue, subjects recited it. In one experiment, the syntactic complexity of the subject and object noun phrase was varied orthogonally. Only subject, but not object, complexity affected onset latencies. Ferreira argued that the subjects retained a semantic-syntactic representation of the sentences in working memory and after presentation of the response cue created the corresponding phonological representation. Apparently, this took more time for syntactically complex than for simple subject noun phrases. Thus, Ferreira proposed that the complete subject noun phrase (e.g., " the man who started the band" or "the pianist in the band") was phonologically encoded before speech onset. This is a substantially larger planning unit than Kempen and Huijbers (1983) and Levelt and Maassen (1981) had proposed.

However, Ferreira's (1991) argument presupposes that the subjects had already con- 
structed a semantic-syntactic representation of the sentence before the response cue was given. Potter and Lombardi (1990; see also Lombardi \& Potter, 1992) showed that in immediate sentence recall tasks subjects do not retain semantic-syntactic representations of sentences but reconstruct them based on conceptual information. Thus, it is uncertain whether Ferreira's results reflect on grammatical or phonological encoding or both.

Finally, Dell and O'Seaghdha (1992) presented subjects with propositional representations of sentences, such as REMOVE (BY BOXER, COAT) or REMOVE (BOXER, COAT), and asked them to prepare to say the corresponding sentences ("The coat was removed by the boxer'" or "The boxer removed the coat"'). On most trials, the preparation period ended with a prompt to say the sentence, but sometimes a probe word (e.g., "shirt" or "coal'") was presented, which the subjects had to name as quickly as possible instead of saying the prepared sentence. The probe could be semantically or phonologically related or unrelated to a target ("coat"' in the example) appearing early or late in the prepared sentence. Reaction times to semantically related or unrelated probes did not differ. However, when the probe word was phonologically related to a target appearing early in the sentence, reaction times were significantly slower than when the probe was unrelated. For targets appearing late in the prepared sentences, the phonological effect was reversed.

When Dell and O'Seaghdha (1991, 1992) used a sentence reiteration instead of the sentence construction task, they replicated the phonological effects and found significant semantic inhibition for targets appearing early and late in the sentences. These findings suggest that the retrieval of all word meanings and forms had begun before sentence onset but that forms at the beginning of the sentence were activated more strongly, or were in other ways more fully prepared, than forms at the end.

To summarize, analyses of speech errors and hesitations suggest that clauses are important planning units at the grammatical level. Levelt and Maassen's (1981) results point in the same direction. By contrast, Lindsley's (1975, 1976) findings suggest that speakers might use subclausal planning units. If Ferreira's (1991) complexity effect arose during grammatical encoding, her results would also support the assumption of subclausal units.

The speech error evidence suggests that the phonological planning units comprise not more than one or two words. Levelt and Maassen's (1981) and Kempen and Huijbers' (1983) findings support this view. However, if Ferreira's (1991) complexity effect arose at the phonological level, it would indicate that phonological planning units can encompass entire complex phrases. Dell and O'Seaghdha's $(1991,1992)$ findings further complicate the picture, as they suggest that before sentence onset different parts of a sentence can be phonologically prepared in different ways or to different degrees.

In short, the picture is far from clear. In the studies just reviewed, different techniques were employed to elicit the utterances, and the utterances varied in syntactic structure. As Schriefers (1992) has pointed out, speakers probably use larger or smaller planning units depending on the circumstances. Thus, the inconsistencies in the results, at least in part, could be due to differences in the speakers' planning strategies.

Even though speakers probably use different planning units in different situations, it is important to find out which units they use in a given situation. In the experiments reported below, Dutch subjects described pictures using noun phrases (e.g., "de pijl en de tas" (the arrow and the bag)) or sentences (e.g., "de pijl staat naast de tas", (the arrow is next to the bag)). The main goal was to establish whether they retrieved the lemma and form of both nouns or of only the first one before speech onset. Once it is known what the planning units for these simple utterances are, more complex descriptive tasks and different syntactic structures can be examined in order to determine whether the planning units are indeed variable, and, if so, what their size depends on.

The paradigm selected for this study is a 
novel version of the picture-word interference paradigm. Subjects were presented with pictures of object pairs. They were instructed to name the objects, starting with the left one, using either noun phrases or, in different experiments, sentences. The pictures were accompanied by auditory distractor words, which could be related in meaning or form to one of the two object names or could be unrelated to both.

In standard picture-word interference experiments, in which only one target object is displayed and named per trial, semantic interference and phonological facilitation can be obtained; i.e., with appropriate timing of the distractors relative to the picture onset, the reaction times are typically longer when target and distractor belong to the same semantic category and shorter when they are phonologically and/ or orthographically related than when they are unrelated (e.g., Glaser \& Düngelhoff, 1984; Lupker, 1979, 1982; Rayner \& Posnansky, 1978; Rayner \& Springer, 1986; Underwood, 1976; Underwood \& Briggs, 1984).

As we have argued elsewhere (Schriefers et al., 1990), the semantic interference effect is likely to arise during the selection of the target lemma rather than at the conceptual level of processing. This view is supported by the finding that the effect was obtained only when subjects named the target objects but not when they performed a picture recognition task, which did not require retrieval of the target names.

A detailed account of the semantic interference effect has recently been proposed by Roelofs (1992). According to Roelofs' model, the distractor lemma, which becomes activated when the distractor is heard, is a competitor to the target lemma. When target and distractor are categorically related, they activate each other via connections to shared conceptual nodes. Thus, in the related condition, the target and the distractor receive more activation than in the unrelated condition. However, for a number of reasons, the target activates the distractor more strongly than vice versa. Thus, the distractor benefits more from the mutual activation than the target. Consequently, the effect of a categorically related distractor relative to an unrelated one is that the selection of the target lemma is delayed.

The facilitatory effect of form-related distractors relative to unrelated ones can be allocated at the level of phonological encoding. When a distractor is processed, its sublexical units become activated. Some of these sublexical units are also part of the target word form. Because of the extra activation these sublexical units receive during distractor processing, they can be selected more rapidly during the phonological encoding of the target than when an unrelated distractor is presented, and the target can therefore be produced sooner (for details see Meyer, 1990, 1991; Meyer \& Schriefers, 1991; Roelofs, 1994).

In the present experiments, the semantic and phonological effects were used to determine which lemmas and word forms were selected before speech onset. Based on earlier research, it was strongly expected that both effects would be obtained for distractors that were related to the first noun. This would indicate that before utterance onset the lemma and form of the first noun are retrieved. If the lemma of the second noun is also retrieved before utterance onset, semantic interference from distractors related to that word could be expected. By contrast, if the lemma of the second noun is retrieved only after utterance onset, no such effect should be found, because a delay in the selection of the lemma of the second noun would not affect the reaction time. Similarly, phonological facilitation for the second noun should be obtained only if the second word form is retrieved before, but not if it is retrieved after, utterance onset.

In Experiments 1 and 2, the effects of semantically related and unrelated distractors, and in Experiments 3 and 4, the effects of phonologically related and unrelated distractors, were compared. In Experiments 1 and 3 , subjects produced noun phrases, and in Experiments 2 and 4, sentences. The features of the method common to all experiments are described under Method in Experiment 1.

\section{EXPERIMENT 1}

\section{Method}

Subjects. The subjects were undergraduate students of Nijmegen University, whose 
native language was Dutch. They were paid for participating in the experiment. Each subject took part in only one experiment. The first experiment was carried out with 30 subjects.

Materials. The visual stimuli were 42 drawings of pairs of target objects shown next to each other. Thirty-six pairs were experimental items, and 6 pairs were practice items. The drawings were selected from the picture pool available at the Max Planck Institute. From a norming study with 20 subjects, it was known how subjects spontaneously named the depicted objects and what the mean naming latency for each object was. The frequencies of the target words were determined using the CELEX database, which is available at the University of Nijmegen and includes a Dutch lexicon of 42 million word tokens. Fifteen nouns appearing on experimental trials and 1 noun appearing on a practice trial were neuter and therefore required the determiner "het'. The other nouns were masculine or feminine and required the determiner " $\mathrm{de}$ "'.

According to the unanimous judgment of five raters, the two targets of each pair belonged to different semantic categories. Across the entire set of materials, the targets in First and Second positions (appearing on the left and right side of the screen, respectively) were matched for mean word frequency (30 vs 39 per million words) and for the mean naming latency in the norming study (782 vs $781 \mathrm{~ms}$ ). The names of the targets of a pair had the same length. There were 18 pairs of monosyllabic and 18 pairs of disyllabic targets. The targets of 10 disyllabic pairs had the same stress pattern, and those of 8 pairs had different stress patterns. The targets of a pair had different onset segments, but they could share up to three segments in other word positions. On average, they shared 0.6 segments.

For each experimental target, a Related distractor that was a member of the same semantic category as the target was selected. For instance, the target "kameel" (camel) was combined with the Related distractor "aap" (monkey). In picture-word interference experiments, distractors that belong to the same semantic category as the targets can slow down the reactions relative to unrelated ones, whereas associatively related distractors can speed them up (LaHeij, Dirkx, \& Kramer, 1990; but see Lupker, 1979). To avoid mutual cancellation of inhibitory and facilitatory effects, distractors that were not highly associated to the targets were selected. As association norms were not available for all targets, a pretest was carried out with the selected target-distractor pairs.

Two groups of 20 subjects each participated in the pretest. One group was presented with a list of the targets in a random order and wrote down their first associate to each of them. The other group did the same for a list of the distractors. It was determined how often the distractors were named as primary associates to the corresponding targets and how often the targets were named as primary associates to the corresponding distractors. Seventy of the 72 target-distractor pairs were not strongly associatively related; i.e., the target was named less than five times as associate to the distractor, and the distractor was named less than five times as associate to the target. For the targets of the two more highly associated pairs, new distractors were selected.

The distractors included between one and four syllables. Targets and distractors were not matched for length or stress pattern. They never shared the onset segment, but they could share up to four segments in other word positions. Across the entire set of materials, the distractors associated with targets in First and Second positions were matched for word frequency (3.3 and 3.7 per million), mean length (1.8 and 1.5 syllables), and the mean number of segments shared with the targets (1.1 and 0.9 segments). The materials are listed in the Appendix.

Each target was also combined with an Unrelated distractor. The Unrelated distractors were identical to the Related ones, but they were combined with targets from a different semantic category. Each distractor was assigned to a target in the same position as the target with which it was combined in the Related condition. The targets and the corresponding Unrelated distractors never shared 
the onset segment but could share up to three segments in other word positions. On average targets in First and Second positions shared 0.8 segments with the Unrelated distractors.

Thus, each experimental picture showed two target objects and was combined with four different distractor words. One word was semantically related to the First and one to the Second target name, and one word was an unrelated control word for the first and one for the second target name. As the same targets and distractors were used in the Related and Unrelated conditions, differences between the conditions could not be due to accidental differences between the pictures or words presented in different conditions.

Finally, in one condition, the subjects heard a stretch of noise instead of an interfering word. A neutral condition in which a nonlinguistic stimulus is presented is often included in picture-word interference experiments to determine whether other types of distractors create facilitation or inhibition relative to this baseline.

Five of the six practice pictures were combined with Unrelated distractors, and one was combined with the stretch of noise.

The distractors began either $150 \mathrm{~ms}$ before or simultaneously with the picture onset. The stimulus onset asynchrony (SOA) of $-150 \mathrm{~ms}$ was used because a strong semantic interference effect had been obtained at this SOA in an earlier experiment (Schriefers et al., 1990). The SOA of $0 \mathrm{~ms}$ was included because it seemed possible that the two target lemmas were activated in sequence and that therefore the semantic interference effect for the second noun might be stronger at a later SOA than that of $-150 \mathrm{~ms}$.

Design. SOA ( -150 and $0 \mathrm{~ms})$ was tested between subjects. The experiment included five conditions defined by the types of distractors. The distractor could be Related to the name of the First or Second target, it could be the Unrelated control word for the First or Second target, or it could be Noise. The five distractor conditions were tested within subjects. Each subject saw each picture five times, each time in combination with a different distractor.
The experiment included five test blocks, in each of which all pictures were presented once. Each picture was assigned to one of five item groups. Four item groups included seven items each, and one included eight. Within each test block, the pictures of each item group were combined with the same type of distractor and those of different item groups with different types of distractors. The order of the five test blocks was balanced across subjects using a latin square design.

The targets were repeated within subjects for three reasons. First, a reasonably large number of data points per subject and condition could be collected; second, these data points stemmed from the same materials for all subjects; and, third, the effects of different distractor types could be evaluated within subjects. A potential weakness of this design is that the effects of the distractors might change across blocks, but the design at least permitted one to examine whether this was the case.

The order of the items within blocks was random and different for each subject. Before the beginning of the first block all practice items were presented once. Before each of the following blocks two randomly selected practice items were repeated.

Apparatus. The experiment was controlled by a Hermac 386 SX computer. The pictures were presented as white line drawings on a black background on a Nec Multisync30 screen. The distractor words were spoken by a female speaker and recorded using a Sony DCT55 DAT recorder. They were digitized with a sampling frequency of $20 \mathrm{kHz}$ and stored on the hard disk of the computer. The mean duration of the distractors was $782 \mathrm{~ms}$. The stretch of noise presented in the baseline condition had the same duration. The auditory stimuli were presented to the subjects using Sennheiser MD211N headphones. The subjects' speech was recorded using a Sennheiser ME400 microphone and a SONY DTC55 DAT recorder. Reaction times were measured using a voice key.

Procedure. Subjects were tested individually. They were seated in a dimly lit soundproof booth at a comfortable viewing distance in front of a monitor. They received a booklet 
including the instructions and pictures of the target objects. Next to each object was printed the noun that the subjects in the norming studies had used spontaneously most frequently to name that object. The subjects were asked to use only these object names. Subjects were informed that they would see pairs of objects, which they should name starting with the left one, using the appropriate definite determiners and the conjunction "en" (and). As soon as they indicated that they had read the instruction and studied the picture names, the first block of trials began. There were pauses of about 1 min between blocks.

The test trials had the following structure. In one group of subjects, the distractor was presented first, followed after $150 \mathrm{~ms}$ by the onset of the picture. In the other group of subjects, the distractor and picture began simultaneously. The picture was presented for $800 \mathrm{~ms}$. The intertrial interval was $3500 \mathrm{~ms}$. The subjects named the picture, and the naming latencies were measured. An experimental session took about $20 \mathrm{~min}$.

Analyses. Three types of responses were categorized as errors: first, incorrect responses, defined as cases where subjects did not use the expected picture names or determiners or omitted part of the utterance; second, disfluencies, defined as trials on which subjects repaired the utterance, stuttered, or produced a clicking or smacking nonspeech sound triggering the voice key; and third, time-outs, defined as responses with latencies longer than $1800 \mathrm{~ms}$. Following Ratcliff (1993), reaction times from error trials were replaced by condition means.

The experiment included five conditions in which different types of distractors were presented. In four conditions subjects heard different types of interfering words, and in the fifth condition, they heard a stretch of noise. Inspection of the condition means of all experiments and SOAs showed that in most cases the reactions were fastest in the Noise condition. Thus, relative to that condition, the other types of distractors produced interference. This result corroborates earlier findings (Meyer \& Schriefers, 1991; Schriefers et al., 1990). For the main questions ad- dressed in the present paper, the results of the Noise condition are not directly relevant. Hence, this condition was not included in the statistical analyses, and the corresponding reaction times and error rates are be reported.

The effects of the remaining four distractor types on reaction times and error rates were determined in analyses of variance with two crossed variables: Relatedness (distractor and target were Related vs Unrelated) and Position (the distractor was Related or Unrelated to the First vs Second noun of the utterance). SOA was crossed with Relatedness and Position.

Each experimental session included five test blocks, in each of which seven or eight items were tested under each distractor condition. In analyses of variance including the variables Block, Relatedness, Position, and SOA, a significant main effect of Block was obtained in each experiment. The mean reaction time decreased by about $50 \mathrm{~ms}$ from the first to the second block and by about $10 \mathrm{~ms}$ with each further block. None of the interactions involving the Block effect approached significance in any of the four experiments. Inspection of the means per distractor condition and block showed that very similar results were obtained in all blocks. In particular, the size of the Relatedness effect did not change systematically across blocks. Therefore, the data were collapsed across blocks in the analyses reported below.

Separate analyses were carried out with subjects and items as random variable, yielding $F 1$ and $F 2$ statistics, respectively. The units of analysis in the item analyses were pictures displaying two objects each. One item was, for instance, the picture showing an arrow and a bag. Relatedness and Position were tested within items and within subjects. SOA was tested between subjects and within items. Unless stated otherwise, effects reported to be significant reached the $1 \%$ level of significance. The analyses of variance on the error rates did not yield any significant effects in any of the four experiments.

\section{Results and Discussion}

The mean reaction times and error rates per condition are shown in Table 1. The error rate 
TABLE 1

Results From ExPERIMENT 1: MEAN Reaction Times (RT) AND Standard ERRors ( $S E$ ) OVER SubJECTS IN Milliseconds AND ERror RATES (e\%) FOR Phrases after Semantically Related and UnRelated DisTRACTORS

\begin{tabular}{lccccc}
\hline \multirow{2}{*}{ Target position: } & \multicolumn{2}{c}{ First } & & \multicolumn{2}{c}{ Second } \\
\cline { 2 - 3 } \cline { 5 - 5 } Distractor: & Related & Unrelated & Related & Unrelated \\
\hline SOA $=-150 \mathrm{~ms}$ & & & & \\
$\mathrm{RT}$ & 851 & 827 & & 850 & 817 \\
SE & 28 & 28 & 29 & 25 \\
$\mathrm{e} \%$ & 14.1 & 10.4 & 11.3 & 10.9 \\
SOA $=0 \mathrm{~ms}$ & & & & \\
$\mathrm{RT}$ & 905 & 883 & 889 & 876 \\
SE & 22 & 22 & 18 & 19 \\
$\mathrm{e} \%$ & 14.4 & 12.6 & 11.1 & 10.7 \\
Mean & & & & \\
$\mathrm{RT}$ & 878 & 855 & 870 & 847 \\
SE & 18 & 18 & 17 & 16 \\
$\mathrm{e} \%$ & 14.3 & 11.5 & 11.2 & 10.8 \\
\hline
\end{tabular}

was higher in the condition where the distractor was related to the First target than in the other conditions, which did not differ much in error rates. The mean reaction time was longest for distractors related to the First target. Hence, there was no speed-accuracy trade-off.

In the analyses of reaction times, only the main effect of Relatedness was significant $(F 1(1,28)=30.66, M S E=527 ; F 2(1,35)=$ $7.58, M S E=5111)$. The mean reaction time was longer after Related than after Unrelated distractors ( 874 vs $851 \mathrm{~ms}$ ). Across the two SOAs, interference effects of exactly equal strength (23 ms) were obtained for the two targets. At SOA $=-150 \mathrm{~ms}$, the interference effect was $24 \mathrm{~ms}$ for the First and $33 \mathrm{~ms}$ for the Second target. At SOA $=0 \mathrm{~ms}$, it was 22 $\mathrm{ms}$ for the First and $13 \mathrm{~ms}$ for the Second target. Neither the interaction between Relatedness and SOA $(F 1(1,28)=2.08, M S E=$ $527 ; F 2(1,35)=1.98, M S E=1329)$, nor the interaction among Relatedness, Position, and $\operatorname{SOA}(F 1(1,28)=1.78, M S E=344 ; F 2(1,35)$ $<1, M S E=2154)$ was significant.

Thus, semantic interference was obtained for both target nouns, which indicates that both lemmas were selected before speech onset. The distractors began either at picture on- set $(\mathrm{SOA}=0 \mathrm{~ms})$ or $150 \mathrm{~ms}$ before picture onset $(\mathrm{SOA}=-150 \mathrm{~ms})$. These two SOAs were tested on the assumption that the second lemma might be selected later than the first, so that semantic interference might arise at a later SOA for the second than for the first noun. The results do not support this assumption but suggest that the selection of the two lemmas overlapped in time.

\section{EXPERIMENT 2}

The second experiment differed from the first only in the structure of the required utterances. Instead of noun phrases, subjects produced short sentences of the form " $X$ staat naast $Y^{\prime}$ ' ( $X$ is next to $Y$ ), where $X$ and $Y$ represent the names of the targets with the appropriate determiners.

\section{Method}

Subjects. Thirty subjects participated in the experiment.

Procedure. The procedure was the same as that used in Experiment 1, except that subjects were now instructed to produce sentences instead of noun phrases.

\section{Results}

Again, only the main effect of Relatedness was significant (means: 820 vs $788 \mathrm{~ms}$ for the Related and Unrelated conditions, respectively; $F 1(1,28)=36.63, M S E=820$; $F 2(1,35)=13.12, M S E=5491)$. Numerically, the interference effect was stronger for the First than for the Second target (38 vs 26 $\mathrm{ms})$, but the interaction between Relatedness and Position was far from significant $(F 1(1,28)=1.73, M S E=596 ; F 2(1,35)<1$, $M S E=5375$; see Table 2). At SOA $=-150$ $\mathrm{ms}$ the interference effect was $28 \mathrm{~ms}$ for the First and $21 \mathrm{~ms}$ for the Second target. At SOA $=0 \mathrm{~ms}$, the effect was $47 \mathrm{~ms}$ for the First and $30 \mathrm{~ms}$ for the Second target. Neither the interaction between Relatedness and SOA $(F 1(1,28)=1.80, M S E=820 ; F 2(1,35)=$ $2.01, M S E=1762)$, nor the interaction of Relatedness with Position and SOA $(F 1(1,28)<$ $1, M S E=596 ; F 2(1,35)<1, M S E=1898)$ was not significant.

Obviously, the results from Experiments 1 
TABLE 2

Results from Experiment 2: Mean Reaction Times (RT) AND Standard ERrors ( $S E$ ) OVER SubJects IN Milliseconds and ERror Rates (e\%) for Sentences after Semantically Related and UnRelated DisTRACTORS

\begin{tabular}{lccccc}
\hline \multirow{2}{*}{ Target position: } & \multicolumn{2}{c}{ First } & & \multicolumn{2}{c}{ Second } \\
\cline { 2 - 3 } \cline { 5 - 5 } Distractor: & Related & Unrelated & Related & Unrelated \\
\hline SOA $=-150 \mathrm{~ms}$ & & & & \\
$\mathrm{RT}$ & 812 & 784 & & 795 & 774 \\
SE & 31 & 29 & 25 & 28 \\
$\mathrm{e} \%$ & 12.0 & 8.5 & 12.8 & 12.8 \\
SOA $=0 \mathrm{~ms}$ & & & & \\
$\mathrm{RT}$ & 841 & 794 & 828 & 798 \\
SE & 22 & 21 & 21 & 26 \\
$\mathrm{e} \%$ & 10.9 & 9.6 & 11.1 & 9.8 \\
Mean & & & & \\
$\mathrm{RT}$ & 827 & 789 & 812 & 786 \\
SE & 19 & 17 & 16 & 19 \\
$\mathrm{e} \%$ & 11.5 & 9.1 & 12.0 & 11.3 \\
\hline
\end{tabular}

and 2 are very similar. In analyses of variance including the data from both experiments, the variable Experiment did not interact with any other variable or interaction. There was, however, a main effect of Experiment $(F 1(1,56)$ $=5.94, M S E=35111, p<.05 ; F 2(1,35)=$ $183.31, M S E=2729)$. The mean reaction time was shorter in Experiment 2, in which the subjects produced sentences, than in Experiment 1 , in which they produced noun phrases (804 vs $863 \mathrm{~ms}$ ). I will return to this finding below. The main conclusion from the first two experiments is that, regardless of utterance structure, subjects selected the meanings of both lemmas before speech onset.

\section{EXPERIMENT 3}

In the third experiment, subjects described the pictures using noun phrase conjunctions, as they had done in Experiment 1. Instead of distractors that were semantically related to one of the target nouns, phonologically related distractors were presented. The main goal was to establish whether before utterance onset only the first, or both, word forms were selected.

\section{Method}

Subjects. Eighty subjects participated in the experiment.
Materials. The visual stimuli were the same as those in Experiments 1 and 2, but new distractors were selected. For each target, a phonologically related distractor, which shared the first two or three segments with the target, was chosen. For instance, the target "slak" (snail) was combined with the distractor "slab" (bib), and the target "sigaar" (cigar) was combined with the distractor "siroop" (syrup). On average, the targets shared 2.6 segments with the Related distractors. Targets and Related distractors had the same number of syllables. With one exception due to an error, disyllabic pairs were matched for stress pattern.

In the Unrelated condition, the same distractors as in the Related condition were used, but they were combined with other targets appearing in the same position (First or Second). Targets and Unrelated distractors had the same number of syllables and, with one exception, the same stress pattern. Monosyllabic targets and their Unrelated distractors did not share any segments. Disyllabic targets and their Unrelated distractors could share one segment in the second syllable. On average, the Unrelated target-distractor pairs shared 0.5 segments. There were no obvious semantic relationships between the members of a pair.

In one condition, the pictures were presented with a stretch of noise instead of an interfering word. The duration of the noise was $796 \mathrm{~ms}$, which was the mean duration of the distractor words in the other conditions.

In a pilot study with these materials an effect of phonological relatedness was obtained only for one of the two targets. Different sets of targets appeared in the two positions, and the corresponding distractors were also different. Therefore, the interaction between Relatedness and Position could be due to differences in the materials used in the two positions. To rule this out, a second version of the pictures in which the positions of the two target objects were reversed was prepared. Each target object was associated with the same distractors in both versions.

Four SOAs, 0, 150, 300, and $450 \mathrm{~ms}$, were tested. At $\mathrm{SOA}=0 \mathrm{~ms}$, distractor and picture 
onset coincided. This SOA was selected because strong phonological facilitation had been obtained at this SOA in earlier experiments (Meyer \& Schriefers, 1991). At the three positive SOAs, the distractors began 150,300 , or $450 \mathrm{~ms}$ after picture onset. These SOAs were included because it seemed possible that the form of the Second target would be activated later than that of the First and that therefore phonological facilitation would be found at a later SOA for the Second than for the First target.

Design. SOA and Picture Version were between-subjects variables. Twenty subjects were tested under each SOA, and 10 subjects within each SOA group received each version of the pictures.

As in Experiments 1 and 2, there were five experimental conditions defined by the types of distractors. The distractor could be Related to the First or Second noun, it could be an Unrelated control word for the First or Second noun, or it could be Noise. These five conditions were tested within subjects using the same design as that used in Experiments 1 and 2.

Procedure. The procedure was the same as that used in Experiment 1, except that the trial structure was changed to test positive SOAs as well as $\mathrm{SOA}=0 \mathrm{~ms}$.

Analyses. The Noise condition was not included in the analyses of variance. Subject and item analyses were carried out on the remaining data points. The unit of analysis for the item analysis was a picture of two objects, regardless of their positions. Thus, the picture of the arrow to the left of the bag and the picture of the arrow to the right of the bag formed one item.

Inspection of the condition means showed that similar results were obtained for the two Picture Versions. In analyses of variance including the variables Picture Version, SOA, Relatedness, and Position, neither the main effect of Picture Version nor the interaction with Relatedness, or with Relatedness and Position, was significant. Hence, for the analyses reported below the data from the two Versions were combined.

\section{TABLE 3}

Results From Experiment 3: Mean Reaction Times (RT) AND STANDARD ERrors ( $S E$ ) OVER SubJECTS IN Milliseconds AND ERror RATEs (e\%) FOR Phrases After Phonologically Related and UnRelated DisTRACTORS

\begin{tabular}{|c|c|c|c|c|}
\hline \multirow{2}{*}{$\begin{array}{l}\text { Target position: } \\
\text { Distractor: }\end{array}$} & \multicolumn{2}{|c|}{ First } & \multicolumn{2}{|c|}{ Second } \\
\hline & Related & Unrelated & Related & Unrelated \\
\hline \multicolumn{5}{|l|}{$\mathrm{SOA}=0 \mathrm{~ms}$} \\
\hline $\mathrm{RT}$ & 803 & 860 & 853 & 842 \\
\hline$S E$ & 31 & 31 & 32 & 30 \\
\hline $\mathrm{e} \%$ & 12.6 & 11.9 & 14.2 & 12.3 \\
\hline \multicolumn{5}{|l|}{$\mathrm{SOA}=150 \mathrm{~ms}$} \\
\hline $\mathrm{RT}$ & 747 & 812 & 795 & 804 \\
\hline$S E$ & 17 & 22 & 19 & 20 \\
\hline $\mathrm{e} \%$ & 10.8 & 10.1 & 11.7 & 11.4 \\
\hline \multicolumn{5}{|l|}{$\mathrm{SOA}=300 \mathrm{~ms}$} \\
\hline $\mathrm{RT}$ & 830 & 885 & 882 & 863 \\
\hline$S E$ & 28 & 31 & 29 & 32 \\
\hline $\mathrm{e} \%$ & 12.6 & 12.1 & 12.9 & 11.5 \\
\hline \multicolumn{5}{|l|}{$\mathrm{SOA}=450 \mathrm{~ms}$} \\
\hline $\mathrm{RT}$ & 734 & 730 & 746 & 739 \\
\hline$S E$ & 18 & 14 & 18 & 17 \\
\hline $\mathrm{e} \%$ & 12.4 & 14.0 & 13.1 & 16.0 \\
\hline \multicolumn{5}{|l|}{ Mean } \\
\hline RT & 779 & 822 & 819 & 812 \\
\hline$S E$ & 13 & 14 & 14 & 14 \\
\hline $\mathrm{e} \%$ & 12.1 & 12.1 & 13.0 & 12.8 \\
\hline
\end{tabular}

\section{Results and Discussion}

The mean reaction times and error rates per condition are displayed in Table 3 . The main effect of Relatedness was significant $(F 1(1,76)$ $=23.16, M S E=1167 ; F 2(1,35)=19.81, M S E$ $=4700)$. As expected, reactions were faster after Related than after Unrelated distractors (means: 799 vs $817 \mathrm{~ms}$ ). However, the effect of Relatedness interacted with other effects. First, the interaction of Relatedness and SOA was significant $(F 1(3,76)=5.76, M S E=1167$; $F 2(3,105)=7.73, M S E=2999)$. There was phonological facilitation at $\mathrm{SOA}=0 \mathrm{~ms}(23$ $\mathrm{ms}), \mathrm{SOA}=150 \mathrm{~ms}(37 \mathrm{~ms})$, and $\mathrm{SOA}=300$ $\mathrm{ms}(18 \mathrm{~ms})$, but not at $\mathrm{SOA}=450 \mathrm{~ms}(6 \mathrm{~ms}$ inhibition). Second, the interaction of Relatedness with Position was significant $(F 1(1,76)$ $=64.18, M S E=799 ; F 2(1,35)=19.17, M S E$ $=9631)$. For the First target, a facilitatory effect of $43 \mathrm{~ms}$, and for the Second target, an inhibitory effect of $7 \mathrm{~ms}$ were obtained. Analyses of simple effects showed that only the first 


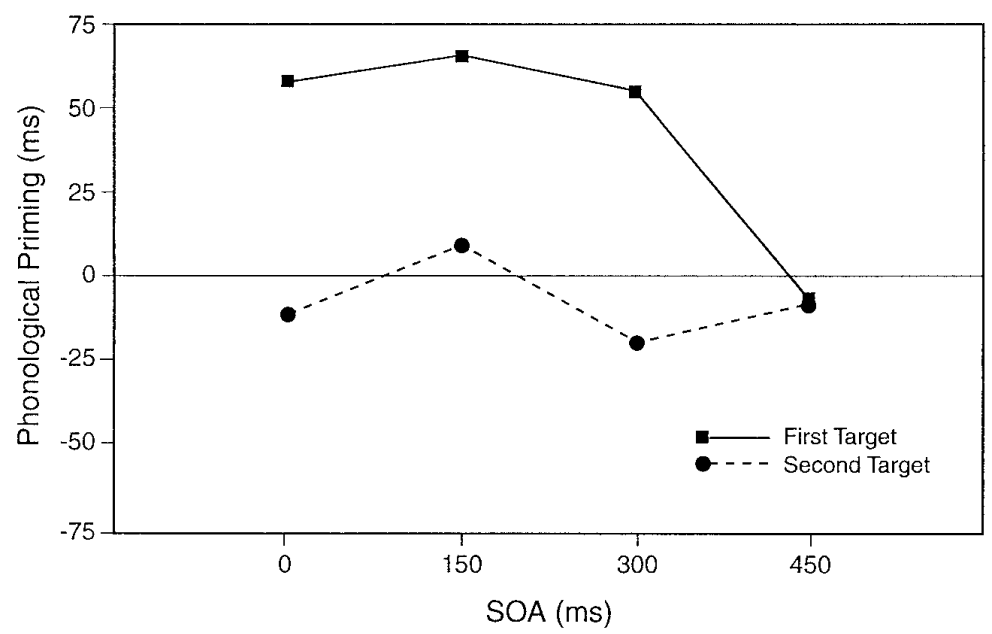

FIG. 1. Phonological priming effects, defined as reaction time differences (in $\mathrm{ms}$ ) between conditions with Unrelated and Phonologically Related distractors for First and Second targets at each SOA in Experiment 3. Positive differences indicate phonological facilitation and negative ones inhibition.

effect was statistically significant $(F 1(1,76)=$ 66.07, $M S E=1135 ; F 2(1,35)=36.35, M S E$ $=7428$ for the First Target; $F 1(1,76)=2.76$, $M S E=781 ; F 2(1,35)=1.12, M S E=6903$ for the Second Target).

The interaction among SOA, Relatedness, and Position was likewise significant ( $F 1$ $(3,76)=6.50, M S E=799 ; F 2(3,105)=6.12$, $M S E=3052$; see Fig. 1). For the First Target, significant facilitatory effects of phonological relatedness of 57,65 , and $55 \mathrm{~ms}$ were obtained at the SOAs of 0,150 , and $300 \mathrm{~ms}$, respectively $(F 1(1,76)=28.85, M S E=1135$; $F 2(1,35)=40.93, M S E=2881$ for $\mathrm{SOA}=$ $0 \mathrm{~ms} ; F 1(1,76)=37.73, M S E=1135$; $F 2(1,35)=19.56, M S E=7884$ for $\mathrm{SOA}=$ $150 \mathrm{~ms} ; F 1(1,76)=26.45, M S E=1135$; $F 2(1,35)=37.67, M S E=2869$ for $\mathrm{SOA}=$ $300 \mathrm{~ms})$. For the Second target, there was a facilitatory effect of $9 \mathrm{~ms}$ at $\mathrm{SOA}=150 \mathrm{~ms}$, and there were inhibitory effects of 11 and 19 $\mathrm{ms}$ at $\mathrm{SOA}=0$ and $\mathrm{SOA}=300 \mathrm{~ms}$, respectively. Only the last mentioned effect approached significance $(F 1(1,76)=4.73, M S E$ $=781, p<.05 ; F 2(1,35)=3.78, M S E=$ $3513, p<.06)$.

Thus, at the first three SOAs, when the distractors began at picture onset or at 150 or $300 \mathrm{~ms}$ after picture onset, the reactions were much faster after distractors that were related to the first noun than after unrelated distractors. This indicates that the form of the first noun was selected before utterance onset. No effect was obtained when the distractors began $450 \mathrm{~ms}$ after picture onset, presumably because at that SOA the distractor was presented too late to systematically affect the retrieval of the form of the first noun.

Reaction times after distractors that were Related or Unrelated to the second noun did not differ significantly at any SOA. As the same targets and distractors were used in the two utterance positions, the confinement of the relatedness effect to the First position cannot be due to properties of the materials. A parsimonious account of the results is that only the form of the first, but not of the second, noun was selected before speech onset.

\section{EXPERIMENT 4}

Experiment 4 differed from Experiment 3 in the structure of the utterances the subjects produced. Instead of noun phrases, they now produced sentences, as the subjects of Experiment 2 had done.

\section{Method}

Subjects. Sixty subjects participated in Experiment 4. 
TABLE 4

Results From ExPERIMENT 4: MEAN Reaction Times (RT) AND StANDARd ERrors ( $S E$ ) OVER SubJECTS IN Milliseconds AND ERror Rates (e\%) FOR SENTENCES after Phonologically Related and UnRelated DisTRACTORS

\begin{tabular}{lccccc}
\hline \multirow{2}{*}{ Target position: } & \multicolumn{2}{c}{ First } & & \multicolumn{2}{c}{ Second } \\
\cline { 2 - 3 } \cline { 5 - 6 } Distractor: & Related & Unrelated & Related & Unrelated \\
\hline SOA = 0 ms & & & & \\
RT & 738 & 803 & & 803 & 783 \\
SE & 21 & 23 & & 22 & 22 \\
e\% & 12.9 & 13.1 & & 11.4 & 12.4 \\
SOA $=150 \mathrm{~ms}$ & & & & \\
RT & 738 & 772 & & 765 & 764 \\
SE & 27 & 25 & & 23 & 24 \\
e\% & 13.2 & 9.3 & & 11.3 & 12.2 \\
SOA $=300 \mathrm{~ms}$ & & & & \\
RT & 711 & 723 & 731 & 717 \\
SE & 14 & 18 & & 18 & 16 \\
e\% & 12.9 & 12.5 & 13.3 & 13.3 \\
Mean & & & & \\
RT & 729 & 766 & 766 & 754 \\
SE & 12 & 13 & 12 & 11 \\
e\% & 13.0 & 11.6 & 12.0 & 12.6 \\
\hline
\end{tabular}

Materials, design, and procedure. No systematic effects of different distractor types had been obtained at $\mathrm{SOA}=450 \mathrm{~ms}$ in Experiment 3. Therefore, this SOA was not tested in Experiment 4. As in Experiment 2, subjects were asked to produce short sentences of the form " $X$ staat naast $Y$,' where $X$ and $Y$ were the names of the two objects with the definite determiners. Otherwise, the materials, procedure, and design were the same as those used in Experiment 3.

\section{Results}

Very similar results were obtained for the two Picture Versions. In analyses of variance, neither the main effect of Picture Version nor any interaction involving this variable approached significance. Hence, the data from the two Versions were combined in the further analyses. The mean reaction times and error rates per condition are shown in Table 4.

The main effect of Relatedness was significant $(F 1(1,57)=11.93, M S E=788$; $F 2(1,35)=6.09, M S E=5553, p<.05)$. The reactions were faster by $12 \mathrm{~ms}$ after Related than after Unrelated distractors (means: 748 vs
$760 \mathrm{~ms})$. The interaction between Relatedness and SOA was also significant $(F 1(2,57)=$ $3.83, M S E=788, p<.05 ; F 2(2,70)=3.25$, $M S E=3342, p<.05)$. At SOA $=0$ and SOA $=150 \mathrm{~ms}$ facilitatory effects of 23 and $17 \mathrm{~ms}$, respectively, were obtained. At $\mathrm{SOA}=300$ $\mathrm{ms}$, the reaction times in the Related and Unrelated conditions differed by only $1 \mathrm{~ms}$.

Most importantly, the interaction between Relatedness and Position was also significant $(F 1(1,57)=46.64, M S E=767 ; F 2(1,35)=$ 22.64, $M S E=5686)$. For the First target, a facilitatory effect of $37 \mathrm{~ms}$, and for the Second target, an inhibitory effect of $12 \mathrm{~ms}$, were obtained. The first of these effects was statistically significant $(F 1(1,57)=58.67, M S E=$ $697 ; F 2(1,35)=25.39, M S E=5800)$; the second reached significance by subjects, but not by items $(F 1(1,57)=4.96, M S E=857$, $p<.05 ; F 2(1,35)=2.81, M S E=5439)$.

Finally, the interaction among SOA, Relatedness, and Position was also significant $(F 1(2,57)=6.18, M S E=767 ; F 2(2,70)=$ 9.07, $M S E=1882$; see Fig. 2). For the First target, significant facilitatory effects of phonological relatedness of 65 and $34 \mathrm{~ms}$ were obtained at the SOAs of 0 and $150 \mathrm{~ms}$, respectively $(F 1(1,57)=58.74, M S E=697$; $F 2(1,35)=73.08, M S E=2018$ for SOA $=$ $0 \mathrm{~ms} ; F 1(1,57)=17.34, M S E=697 ; F 2(1,35)$ $=10.57, M S E=4119$ for $\mathrm{SOA}=150 \mathrm{~ms})$. At $\mathrm{SOA}=300 \mathrm{~ms}$, a facilitatory effect of 12 ms was found, which was not significant. For the Second target, an inhibitory effect of 20 $\mathrm{ms}$ was obtained at SOA $=0 \mathrm{~ms}$, which was significant in the subject, but not in the item analysis $(\mathrm{F} 1(1,57)=4.67, M S E=857, p<$ $.05 ; F 2(1,35)=3.78, M S E=3814, p<.06)$. At $\mathrm{SOA}=150 \mathrm{~ms}$, the reaction times in the Related and Unrelated conditions differed by only $1 \mathrm{~ms}$. At SOA $=300 \mathrm{~ms}$ an inhibitory effect of $14 \mathrm{~ms}$ was found, which was not significant.

The results from Experiments 3 and 4 were similar in that phonological facilitation was obtained only for the First but not for the Second target, but they differed in two ways. First, the mean reaction time was considerably faster in Experiment 4 than in Experiment 3 (754 vs $831 \mathrm{~ms}$ ). In analyses of variance 


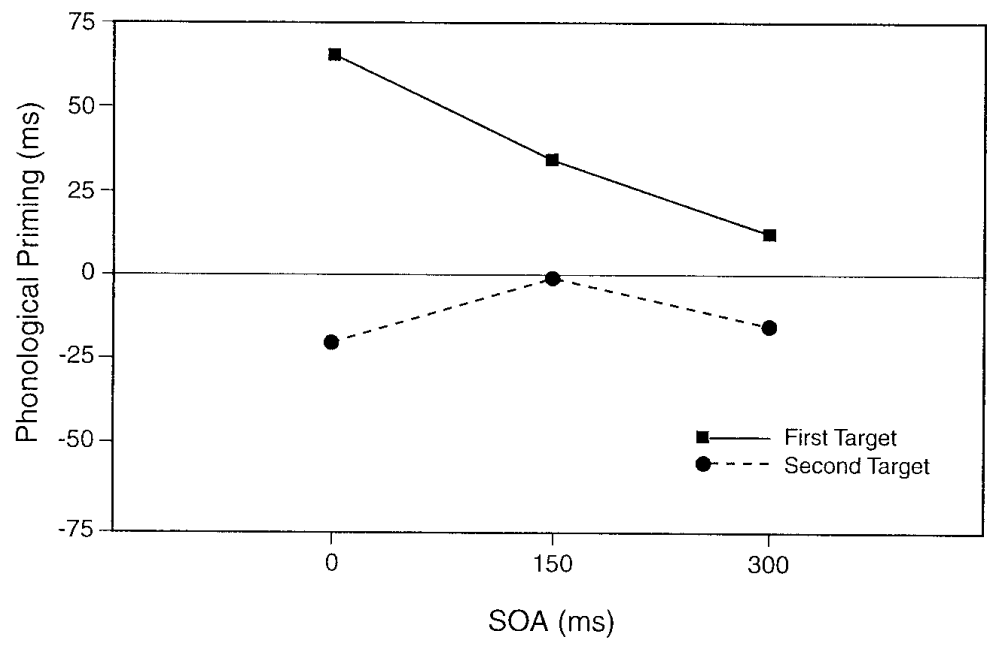

FIG. 2. Phonological priming effects, defined as reaction time differences (in $\mathrm{ms}$ ) between conditions with Unrelated and Phonologically Related distractors for First and Second targets at each SOA in Experiment 4. Positive differences indicate phonological facilitation and negative ones inhibition.

across both experiments excluding SOA = $450 \mathrm{~ms}$ in Experiment 3, this difference was significant $F 1(1,114)=15.52, M S E=46207$; $F 2(1,35)=431.32, M S E=5987)$. As in Experiments 1 and 2, subjects were faster to initiate sentences than phrases. Second, in Experiment 4 , significant facilitation for the First Target was obtained only at the SOAs of 0 and $150 \mathrm{~ms}$, whereas in Experiment 3, it was also found at the SOA of $300 \mathrm{~ms}$. These differences among the experiments are probably related to each other. The finding that the utterances were initiated faster in Experiment 4 than in Experiment 3 suggests that the first noun was encoded earlier in the former than in the latter experiment. Therefore, a distractor presented $300 \mathrm{~ms}$ after picture onset could still affect phonological encoding in Experiment 3, but came too late to affect it in Experiment 4. The interaction among Experiment, SOA, Relatedness, and Position was significant by subjects $(F 1(2,114)=3.08, M S E=821, p<$ $.05)$ and almost significant by items $(F 2(2,70)$ $=3.07, M S E=2939, p<.06)$. The interaction between Relatedness and Experiment reached significance $(F 1(1,114)=5.10, M S E$ $=1078, p<.05 ; F 2(1,35)=7.74, M S E=$ 2531), reflecting the fact that, across SOAs, the Relatedness effect was slightly larger in Experiment 3 than in Experiment 4 (18 vs
$12 \mathrm{~ms})$. The interaction among Experiment, Relatedness, and Position was not significant $(F 1(1,114)=2.82, M S E=821 ; F 2(1,35)=$ 2.18, MSE = 3804).

In spite of the differences between Experiments 3 and 4, the main conclusion is the same. Strong phonological facilitation was found for the First, but not for the Second, target, suggesting that only the first noun was phonologically encoded before speech onset.

\section{General Discussion}

As noted in the Introduction, most models of language production assume that lemmas and forms of words are stored separately in the mental lexicon so that the lemma of a word can be selected without its form. The present findings support this view as they show that before speech onset the lemma, but not the form of the second target noun, was selected. The findings are also consistent with the speech error evidence demonstrating that speakers use larger planning units at the grammatical than at the phonological level of processing.

The conclusion that the grammatical planning unit encompassed the entire utterance is compatible with evidence from analyses of speech errors and pauses supporting the clause as an important planning unit at the grammati- 
cal level. However, the experimental evidence obtained by Lindsley (1975) and Levelt and Maassen (1981) can be taken as supporting the assumption of subclausal grammatical planning units. Perhaps different processes were tapped in the present and in the earlier experimental studies. The present experiments were designed to determine whether the subjects selected lemma and word form of both nouns or only of the first one before utterance onset. This could be inferred from the effects of semantically and phonologically Related relative to Unrelated distractors. By contrast, in the earlier studies inferences about planning units were based on speech onset latencies for utterances differing in syntactic structure. Lindsley (1975) compared speech onset latencies for subject-only, subject-verb, and subject-verb-object utterances. Levelt and Maassen (1981) compared speech onset latencies for sentences beginning with a noun phrase conjunction or a simple noun phrase. The obtained reaction time differences could indicate, as Lindsley and Levelt and Maassen proposed, that the number of lemmas selected before speech onset differed for different constructions or that syntactic processing was more time-consuming for some constructions than for others.

A result of the present study supporting the latter hypothesis is that the mean onset latencies were significantly longer for noun phrases than for sentences. Yet, the semantic interference effects show that, for both types of utterances, the lemmas of both target nouns and the form of the first one were selected before speech onset. Thus, the difference in onset latencies did not arise during lexical selection but, most likely, during the generation of the syntactic structure. Perhaps the syntactic effect found by Levelt and Maassen (1981) and Lindsley (1975) had a similar origin.

An alternative way to explain the difference between the present and the earlier results is that speakers choose different types of planning units under different circumstances, as Schriefers (1992) has suggested. Perhaps they use smaller grammatical planning units when the descriptive task is more difficult. In the experiments reported here, the subjects' task was extremely simple. On each trial they had to name two objects inserting a constant conjunction or a verb and a preposition between the object names. In Lindsley's (1975) subject-verb-object condition and in Levelt and Maassen's (1981) experiment, utterance planning was probably more difficult because subjects had to name not only two entities but also a variable action or movement. Thus, subjects might have been more likely to use subclausal planning units in these than in the present experiments because message generation and/or utterance formulation were more difficult.

In Experiments 3 and 4, phonological facilitation was obtained only for the First, but not for the Second, target. This result supports the conclusion drawn by Levelt and Maassen (1981) and by Kempen and Huijbers (1983) that the phonological planning units do not comprise more than one or two words. However, distractors that were phonologically related to the second noun yielded an inhibitory effect. This effect was weak (7 ms in Experiment 3 and $12 \mathrm{~ms}$ in Experiment 4) compared to the facilitatory effect obtained for the first noun $(43 \mathrm{~ms}$ in Experiment 3 and $37 \mathrm{~ms}$ in Experiment 4) and did not reach significance across SOAs or at any individual SOA in either experiment. However, it came close to reaching significance at one SOA (albeit not the same one) in each experiment and therefore deserves some consideration.

This effect may have arisen because early activation of the form of the second noun interfered with the phonological encoding of the first noun. Following Dell (1986), I assume that words are phonologically encoded sequentially, according to their order in the utterance, which is specified during grammatical encoding. When two lemmas have been selected, they both activate their sublexical units, but the first one initially activates them more strongly than the second. Therefore, the sublexical units of the first word are selected first. When a distractor is presented that is phonologically related to the first noun, some of the sublexical units of that noun receive extra activation, so that they can be selected more rapidly than when an unrelated distractor is presented, and the utterance can be initiated sooner. When the distractor is related to the second noun, 
activation is added to the sublexical units of a competitor to the noun that must be phonologically encoded first. This could lead to an increase in naming latency if the time necessary to select the sublexical units of the first noun depends not only on their own activation levels but also on the activation levels of competing units (see, for instance, Roelofs, 1992).

Thus, it is proposed that the two nouns must be phonologically encoded in sequence and that early activation of the second word form interferes with the phonological encoding of the first word. This account implies that although only the first word form is selected before utterance onset, both word forms are activated to some extent. This assumption is compatible with Dell and O'Seaghdha's (1992) suggestion that the forms of words in different sentence positions may be prepared to different degrees or in different ways before utterance onset.

The present results, together with those from studies of lexical access to single words, suggest the following view of lexical access in connected speech. First, the message activates one or more lexical concepts and the associated lemmas. As soon as a lemma has been selected, the corresponding sublexical units begin to be activated. If several lemmas are selected more or less at the same time, several sets of form units are activated in parallel. However, the selection of sublexical units for different words is a sequential process.

To replace this sketch by a model, more information about the time course of lexical access is required. In Experiments 1 and 2, semantic interference was found for both nouns at both SOAs. This suggests that access to the two lemmas overlapped in time, but it does not reveal whether access to the two lemmas began at the same or different moments in time. Schriefers (1992) has argued that the lemmas of adjective-noun phrases are accessed in parallel, but it is not certain that this also holds for different syntactic constructions. An important question for further research is whether speakers retrieve several lemmas in parallel, and if so, how many.
The time course of phonological encoding also needs further study. It was speculated above, first, that several selected lemmas might activate their forms in parallel, and, second, that the selection of sublexical units for different words is a sequential process. Both of these claims must still be tested. There is evidence that successive parts of a word are phonologically encoded in sequence (Meyer, 1990, 1991; Meyer \& Schriefers, 1991; Wheeldon \& Levelt, 1995), but this does not rule out the possibility that successive words could be encoded in parallel. As mentioned in the Introduction, phonological encoding involves a number of processes, including the activation and selection of segments, the generation of word or syllable frames, the association of segments to frames, and the selection of articulatory programs. It remains to be determined which of these processes are sequential within and between words.

The above discussion of the experimental results presupposed that the semantic and phonological effects arose during utterance formulation rather than during conceptual processing. One might argue, however, that the semantic effect arose at the conceptual level. As noted in the Introduction, Schriefers et al. (1990) showed that the semantic effect disappeared when subjects performed a picture recognition rather than a picture naming task. This argues against a conceptual locus of the effect. However, it is not certain that the memory representations used in picture recognition were the same as those used in picture naming. Consequently, it can be argued that the null effect in the recognition experiment does not rule out a conceptual locus of the effect in the naming experiment. Therefore, an alternative account of the present data is that before utterance onset both targets are processed at the conceptual level, but only the first one is phonologically encoded. The span of advance planning at the grammatical level is unknown. A challenge for future research is to find new ways to discriminate between conceptual and grammatical planning and to examine how these planning processes are coordinated with each other. 
APPENDIX: MATERIALS

Target

slak (snail)

berg (hill)

$\operatorname{arm}(\operatorname{arm})$

tol (top)

kruis (cross)

bank (couch)

kan (can)

jurk (dress)

kok (cook)

ster (star)

step (scooter)

hoed (hat)

schip (ship)

kaas (cheese)

beer (bear)

harp (harp)

schaar (scissors)

pop (doll)

vaas (vase)

broek (pants)

boom (tree)

vlag (flag)

bot (bone)

maan (moon)

zaag (saw)

bus (bus)

kam (comb)

wieg (wheel)

pijl (arrow)

tas (bag)

kerk (church)

fluit (flute)

bom (bomb)

hand (hand)

tent (tent)

vork (fork)

Semantically related distractor Phonologically related distractor

worm (worm)
weide (meadow)
voet (foot)
knikker (marble)
driehoek (triangle)
dressoir (sideboard)
beker (mug)
blouse (blouse)
bakker (baker)
meteoor (meteor)

rolschaats (roller-skate)

pet (cap)

onderzëëer (submarine)

boter (butter)

tijger (tiger)

trompet (trumpet)

lijm (glue)

teddy beer (teddy bear)

pot (jar)

trui (sweater)

struik (bush)

wapen (weapon)

spier (muscle)

planeet (planet)

tang (tongs)

tram (tram)

shampoo (shampoo)

band (tire)

speer (spear)

koffer (suitcase)

moskee (mosque)

hoorn (horn)

mijn (mine)

oor (ear)

caravan (trailer)

servet (napkin) slab (bib)

bel (bell)

arts (doctor)

ton (barrel)

kruid (herb)

bad (bathtub)

kalf (calf)

juf (teacher)

komst (arrival)

stelt (stilt)

stel (pair)

hoek (corner)

schil (peel)

kaart (card)

beek (creek)

ham (ham)

schaats (skate)

post (mail)

vaart (speed)

broer (brother)

boor (drill)

vlas (flax)

bos (forest)

maag (stomach)

zaad (seed)

bult (bump)

kast (closet)

wieg (cradle)

pijp (pipe)

tand (tooth)

kers (cherry)

fluim (phlegm)

bok (goat)

hark (rake)

test (test)

vonk (spark) 
APPENDIX - Continued

\begin{tabular}{|c|c|c|}
\hline Target & Semantically related distractor & Phonologically related distractor \\
\hline $\begin{array}{l}\text { citroen (lemon) } \\
\text { tafel (table) }\end{array}$ & $\begin{array}{l}\text { mandarijn (mandarin) } \\
\text { bed (bed) }\end{array}$ & $\begin{array}{l}\text { citaat (quotation) } \\
\text { tante (aunt) }\end{array}$ \\
\hline $\begin{array}{l}\text { masker (mask) } \\
\text { borstel (brush) }\end{array}$ & $\begin{array}{l}\text { schmink (make-up) } \\
\text { gel (gel) }\end{array}$ & $\begin{array}{l}\text { massa (mass) } \\
\text { bobbel (bubble) }\end{array}$ \\
\hline $\begin{array}{l}\text { geweer (gun) } \\
\text { tractor (tractor) }\end{array}$ & $\begin{array}{l}\text { mitrailleur (machine gun) } \\
\text { ploeq (plow) }\end{array}$ & $\begin{array}{l}\text { gezwets (bragging) } \\
\text { traptree (step) }\end{array}$ \\
\hline $\begin{array}{l}\text { konijn (rabbit) } \\
\text { lepel (spoon) }\end{array}$ & $\begin{array}{l}\text { marmot (marmot) } \\
\text { glass (glass) }\end{array}$ & $\begin{array}{l}\text { kolom (column) } \\
\text { leger (army) }\end{array}$ \\
\hline $\begin{array}{l}\text { kikker (frog) } \\
\text { vliegtuig (plane) }\end{array}$ & $\begin{array}{l}\text { pad (path) } \\
\text { helicopter (helicopter) }\end{array}$ & $\begin{array}{l}\text { kinkel (lout) } \\
\text { vlierbes (elderberry) }\end{array}$ \\
\hline $\begin{array}{l}\text { kanon (cannon) } \\
\text { sigaar (cigar) }\end{array}$ & $\begin{array}{l}\text { tank (tank) } \\
\text { pijp (pipe) }\end{array}$ & $\begin{array}{l}\text { kaneel (cinnamon) } \\
\text { siroop (syrup) }\end{array}$ \\
\hline $\begin{array}{l}\text { banaan (banana) } \\
\text { fontein (fountain) }\end{array}$ & $\begin{array}{l}\text { sinaasappel (orange) } \\
\text { standbeeld (statue) }\end{array}$ & $\begin{array}{l}\text { bacil (bacillus) } \\
\text { fornuis (oven) }\end{array}$ \\
\hline $\begin{array}{l}\text { gitaar (guitar) } \\
\text { fabriek (factory) }\end{array}$ & $\begin{array}{l}\text { banjo (banjo) } \\
\text { kantoor (office) }\end{array}$ & $\begin{array}{l}\text { gigant (giant) } \\
\text { fazant (pheasant) }\end{array}$ \\
\hline $\begin{array}{l}\text { kasteel (castle) } \\
\text { hamer (hammer) }\end{array}$ & $\begin{array}{l}\text { paleis (palace) } \\
\text { vijl (file) }\end{array}$ & $\begin{array}{l}\text { kandij (candy) } \\
\text { haring (herring) }\end{array}$ \\
\hline $\begin{array}{l}\text { schommel (swing) } \\
\text { raket (rocket) }\end{array}$ & $\begin{array}{l}\text { glijbaan (slide) } \\
\text { kunstmaan (satellite) }\end{array}$ & $\begin{array}{l}\text { schorsing (suspension) } \\
\text { radijs (radish) }\end{array}$ \\
\hline $\begin{array}{l}\text { ketel (cattle) } \\
\text { ballon (balloon) }\end{array}$ & $\begin{array}{l}\text { pan (frying pan) } \\
\text { slinger (garland) }\end{array}$ & $\begin{array}{l}\text { kever (beatle) } \\
\text { bassist (bass) }\end{array}$ \\
\hline $\begin{array}{l}\text { kameel (camel) } \\
\text { orgel (organ) }\end{array}$ & $\begin{array}{l}\text { aap (ape) } \\
\text { piano (piano) }\end{array}$ & $\begin{array}{l}\text { kanaal (channel) } \\
\text { orde (order) }\end{array}$ \\
\hline $\begin{array}{l}\text { gieter (watering can) } \\
\text { varken (piglet) }\end{array}$ & $\begin{array}{l}\text { schoffel (hoe) } \\
\text { koe (cow) }\end{array}$ & $\begin{array}{l}\text { giro (gyro) } \\
\text { varen (fern) }\end{array}$ \\
\hline $\begin{array}{l}\text { cactus (cactus) } \\
\text { fietspomp (bike-pump) }\end{array}$ & $\begin{array}{l}\text { vetplant (succulent plant) } \\
\text { ventiel (valve) }\end{array}$ & $\begin{array}{l}\text { canvas (canvas) } \\
\text { fiedel (fiddle) }\end{array}$ \\
\hline $\begin{array}{l}\text { anker (anchor) } \\
\text { gordijn (curtain) }\end{array}$ & $\begin{array}{l}\text { loopplank (gangway) } \\
\text { behang (wallpaper) }\end{array}$ & $\begin{array}{l}\text { angel (hook) } \\
\text { gordel (belt) }\end{array}$ \\
\hline $\begin{array}{l}\text { hengel (fishing rod) } \\
\text { viool (violin) }\end{array}$ & $\begin{array}{l}\text { dobber (float) } \\
\text { cello (cello) }\end{array}$ & $\begin{array}{l}\text { hennep (hemp) } \\
\text { vizier (visor) }\end{array}$ \\
\hline $\begin{array}{l}\text { motor (motorbike) } \\
\text { vinger (finger) }\end{array}$ & $\begin{array}{l}\text { auto (car) } \\
\text { teen (toe) }\end{array}$ & $\begin{array}{l}\text { mode (fashion) } \\
\text { vinding (invention) }\end{array}$ \\
\hline $\begin{array}{l}\text { bezem (broom) } \\
\text { vierkant (square) }\end{array}$ & $\begin{array}{l}\text { dweil (rag) } \\
\text { rechthoek (rectangle) }\end{array}$ & $\begin{array}{l}\text { beving (tremor) } \\
\text { viespeuk (dirty pig) }\end{array}$ \\
\hline
\end{tabular}

Note. The two targets of an item and the associated distractors are listed on successive lines. 


\section{REFERENCES}

BIERWISCH, M., \& Schreuder, R. (1992). From concepts to lexical items. Cognition, 42, 23-60.

Bock, K., \& LeVelt, W. (1994). Grammatical encoding. In M.A. Gernsbacher (Ed.), Handbook of Psycholinquistics (pp. 945-984). San Diego: Academic Press.

Brown, A. S. (1991). A review of the Tip-of-the-Tongue Experience. Psychological Bulletin, 109, 204-223.

Burke, D. M., MacKay, D. G., Worthley, J. S., \& WADE, E. (1991). On the tip of the tongue: What causes word finding failures in young and older adults? Journal of Memory and Language, 30, $542-$ 579.

ButTerworth, B. (1992). Disorders of phonological encoding. Cognition, 42, 261-286.

DeLl, G. S. (1986). A spreading-activation theory of retrieval in sentence production. Psychological Review, 93, 283-321.

Dell, G. S., \& O'Seaghdha, P. G. (1991). Mediated and convergent lexical priming in language production: A comment on Levelt et al. (1991). Psychological Review, 98, 604-614.

Dell, G. S., \& O'Seaghdha, P. G. (1992). Stages of lexical access in language production. Cognition, 42, 287-314.

FERREIRA, F. (1991). Effects of length and syntactic complexity on initiation times for prepared utterances. Journal of Memory and Language, 30, 210-233.

ForD, M. (1982). Sentence planning units: Implications for the speaker's representation of meaningful relations underlying sentences. In J. Bresnan (Ed.), The mental representation of grammatical relations (pp. 797-827). Cambridge, MA: MIT Press.

Ford, M., \& Holmes, V. M. (1978). Planning units and syntax in sentence production. Cognition, 6, 35-53.

GARRETT, M. F. (1980). Levels of processing in sentence production. In B. Butterworth (Ed.), Language Production, Vol. 1. Speech and Talk (pp. 177-230). New York: Academic Press.

GARRETT, M. F. (1982). Production of speech: Observations from normal and pathological language use. In A. Ellis (Ed.), Normality and pathology in cognitive functions (pp. 19-76). London: Academic Press.

GARRETT, M. F. (1988). Processes in language production. In F. J. Newmeyer (Ed.), Linguistics: The Cambridge Survey: III. Language: Psychological and biological aspects (pp. 69-96). Cambridge: Cambridge University Press.

Garrett, M. (1992). Disorders of lexical selection. Cognition, 42, 143-180.

Glaser, W. R., \& Düngelhoff, F.-J. (1984). The time course of picture-word interference. Journal of Experimental Psychology: Human Perception and Performance, 8, 875-894.

Goodglass, H., Kaplan, E., Weintraub, S., \& AckerMAN, N. (1976). The "tip-of-the-tongue" phenomenon in aphasia. Cortex, 12, 143-153.

Holmes, V. M. (1988). Hesitations and sentence plan- ning. Language and Cognitive Processes, 3, 323361.

Kempen, G., \& HuijBers, P. (1983). The lexicalization process in sentence production and naming: Indirect election of words. Cognition, 14, 185-209.

LaHeis, W., Dirkx, J., \& Kramer, P. (1990). Categorical interference and associative priming in picture naming. British Journal of Psychology, 81, 511-525.

Le Dorze, G., \& Nespoulous, J.-L. (1989). Anomia in moderate aphasia: Problems in accessing the lexical representation. Brain and Language, 37, 381-400.

Levelt, W. J. M. (1989). Speaking: From intention to articulation. Cambridge, MA: MIT Press.

Levelt, W. J. M. (1992). Accessing words in speech production: Stages, processes and representations. Cognition, 42, 1-22.

Levelt, W., \& MaAssen, B. (1981). Lexical search and order of mention in sentence production. In W. Klein and W. Levelt (Eds.), Crossing the boundaries in linguistics (pp. 221-252). Dordrecht: Reidel.

Levelt, W. J. M., Schriefers, M., Vorberg, D., Meyer, A. S., Pechmann, T., \& Havinga, J. (1991). The time course of lexical access in speech production: A study of picture naming. Psychological Review, 98, 122-142.

Levelt, W. J. M., \& WheEldon, L. (1994). Do speakers have access to a mental syllabary? Cognition, 50, 239-269.

LiNDSLEY, J. R. (1975). Producing simple utterances: How far ahead do we plan? Cognitive Psychology, 7, 119.

LinDSLEY, J. R. (1976). Producing simple utterances: Details of the planning process. Journal of Psycholinguistic Research, 5, 331-354.

Lombardi, L., \& POTTER, M. C. (1992). The regeneration of syntax in short-term memory. Journal of Memory and Language, 31, 713-733.

LUPKER, S. J. (1979). The semantic nature of response competition in the picture-word interference task. Memory \& Cognition, 7, 485-495.

LUPKER, S. J. (1982). The role of phonetic and orthographic similarity in picture-word interference. $\mathrm{Ca}$ nadian Journal of Psychology, 36, 349-367.

Meyer, A. S. (1990). The time course of phonological encoding in language production: The encoding of successive syllables of a word. Journal of Memory and Language, 29, 524-545.

Meyer, A. S. (1991). The time course of phonological encoding in language production: Phonological encoding inside a syllable. Journal of Memory and Language, 30, 69-89.

Meyer, A. S., \& Schriefers, H. (1991). Phonological facilitation in picture-word interference experiments: Effects of stimulus onset asynchrony and types of interfering stimuli. Journal of Experimental Psychology: Learning, Memory, and Cognition, 17, 11461160.

PotTer, M. C., \& LombARDI, L. (1990). Regeneration in the short-term recall of sentences. Journal of Memory and Language, 29, 633-654. 
RATCLIFF, R. (1993). Methods for dealing with reaction time outliers. Psychological Review, 3, 510-532.

RAYner, K., \& Posnansky, C. (1978). Stages of processing in word identification. Journal of Experimental Psychology: General, 107, 64-80.

RAYNER, K., \& SPRINGER, C. J. (1986). Graphemic and semantic effects in the picture-word interference task. British Journal of Psychology, 77, 207-222.

Roelofs, A. (1992). A spreading-activation theory of lemma retrieval in speaking. Cognition, 42, 107142.

Roelofs, A. (1994). On-line versus off-line priming of word-form encoding in spoken word production. In A. Ram \& K. Eiselt (Eds.), Proceedings of the Sixteenth Annual Conference of the Cognitive Science Society (pp. 772-772). Hillsdale, NJ: Lawrence-Erlbaum.

SCHRIEFERS, H. (1992). Lexical access in the production of noun phrases. Cognition, 45, 33-54.

SCHRIEFERS, H. (1993). Syntactic processes in the produc- tion of noun phrases. Journal of Experimental Psychology: Learning, Memory, and Cognition, 19, $841-850$.

Schriefers, H., Meyer, A. S., \& Levelt, W. J. M. (1990). Exploring the time course of lexical access in language production: Picture-word interference studies. Journal of Memory and Language, 29, 86102.

UNDERWOOD, G. (1976). Semantic interference from unattended printed words. British Journal of Psychology, 67, 327-338.

Underwood, G., \& Briggs, P. (1984). The development of word recognition processes. British Journal of Psychology, 75, 243-255.

WheEldon, L. R., \& Levelt, W. J. M. (1995). Monitoring the time-course of phonological encoding. Journal of Memory and Language, 34, 311-334.

(Received February 8, 1995)

(Revision received May 25, 1995) 